Article

\title{
Deep Control of Linear Oligomerization of Glycerol Using Lanthanum Catalyst on Mesoporous Silica Gel
}

\author{
Daniela Caputo ${ }^{1,2}$, Michele Casiello ${ }^{1}{ }^{1}$, Antonella Milella ${ }^{1}$, Werner Oberhauser ${ }^{3}$, \\ Alfonso Maffezzoli ${ }^{4}\left(\mathbb{D}\right.$, Angelo Nacci ${ }^{1,2}{ }^{\mathbb{D}}$, Caterina Fusco ${ }^{2}$ (D) and Lucia $D^{\prime}$ Accolti ${ }^{1,2, *(D)}$ \\ 1 Dipartimento di Chimica, Università degli Studi di Bari “A. Moro”, Via Orabona 4, 70126 Bari, Italy; \\ daniela.caputo@uniba.it (D.C.); michele.casiello@uniba.it (M.C.); antonella.milella@uniba.it (A.M.); \\ angelo.nacci@uniba.it (A.N.) \\ 2 CNR-Istituto di Chimica dei Composti Organometallici (ICCOM), Bari section, via Orabona 4, \\ 70126 Bari, Italy; fusco@ba.iccom.cnr.it \\ 3 CNR-Istituto di Chimica dei Composti Organometallici (ICCOM), Area della Ricerca CNR di Firenze, \\ Via Madonna del Piano 10, 50019 Sesto Fiorentino, Italy; werner.oberhauser@iccom.cnr.it \\ 4 Dipartimento di Ingegneria dell'Innovazione Centro Ecotekne Pal. O - S.P. 6, 73047 \\ Lecce-Monteroni-LECCE (LE), Italy; alfonso.maffezzoli@unisalento.it \\ * Correspondence: lucia.daccolti@uniba.it
}

Received: 13 September 2020; Accepted: 10 October 2020; Published: 12 October 2020

check for updates

\begin{abstract}
The valorization of glycerol (1), a waste of biodiesel production of Fatty Acid Methyl Esters (FAMEs), adopting a "green" approach, represents an important goal of sustainable chemistry. While the polymerization of $\mathbf{1}$ to hyperbranched oligomers is a well-established process, the linear analogues are difficult to obtain. In this context, we explore the reaction without the solvent of heterogeneous hybrid La(III)O-KIT-6 catalyst (2), which is based on lanthanum oxide on mesoporous silica gel, showing a superior linear selectivity compared to most of the analogous catalysts recently reported.
\end{abstract}

Keywords: heterogeneous catalysis; green chemistry; linear polyglycerol

\section{Introduction}

Glycerol (1) (1,2,3-propanetriol) is a non-toxic, edible, biosustainable and biodegradable compound. It is easily obtained from the fermentation of glucose, hydrogenolysis of sorbitol, and as by-product of biodiesel production from vegetable oils [1]. Recently, it has gained great attention as an attractive building block of organic synthesis [2,3] and as a starting material for the preparation of polyglycerols [4,5], which are a class of oligomeric materials that are gaining growing interest in cosmetics, polymers, foods, lubricants, plasticizers, stabilizers, and pharmaceutical industries, as well as in the drug delivery field [6]. While considerable attention has been focused on hyperbranched polyglycerols synthesis [7], less success has been attained in the direct selective synthesis of linear polyglycerols [6,8], which are innovative oligomers displaying potential applications in biomedical and coating materials fields [8]. In fact, linear polyglycerols are essentially used as surfactants after conversion to fatty acid esters, and they can replace polyethylene glycol (PEG), which is produced from ethylene oxide of petroleum origin. In the last few years, linear polyglycerols are gaining interest as a promising biomedical material because they may have high hydroxyl content functionality, allowing for a wide range of further modifications and applications [8].

To date, the synthesis of linear polyglycerols can be achieved through three different approaches: (i) direct etherification of unprotected glycerol under basic conditions [4], (ii) starting from protected glycidol monomers [4], and (iii) using protected derivatives and acidic deprotection [9] (Chart 1). 

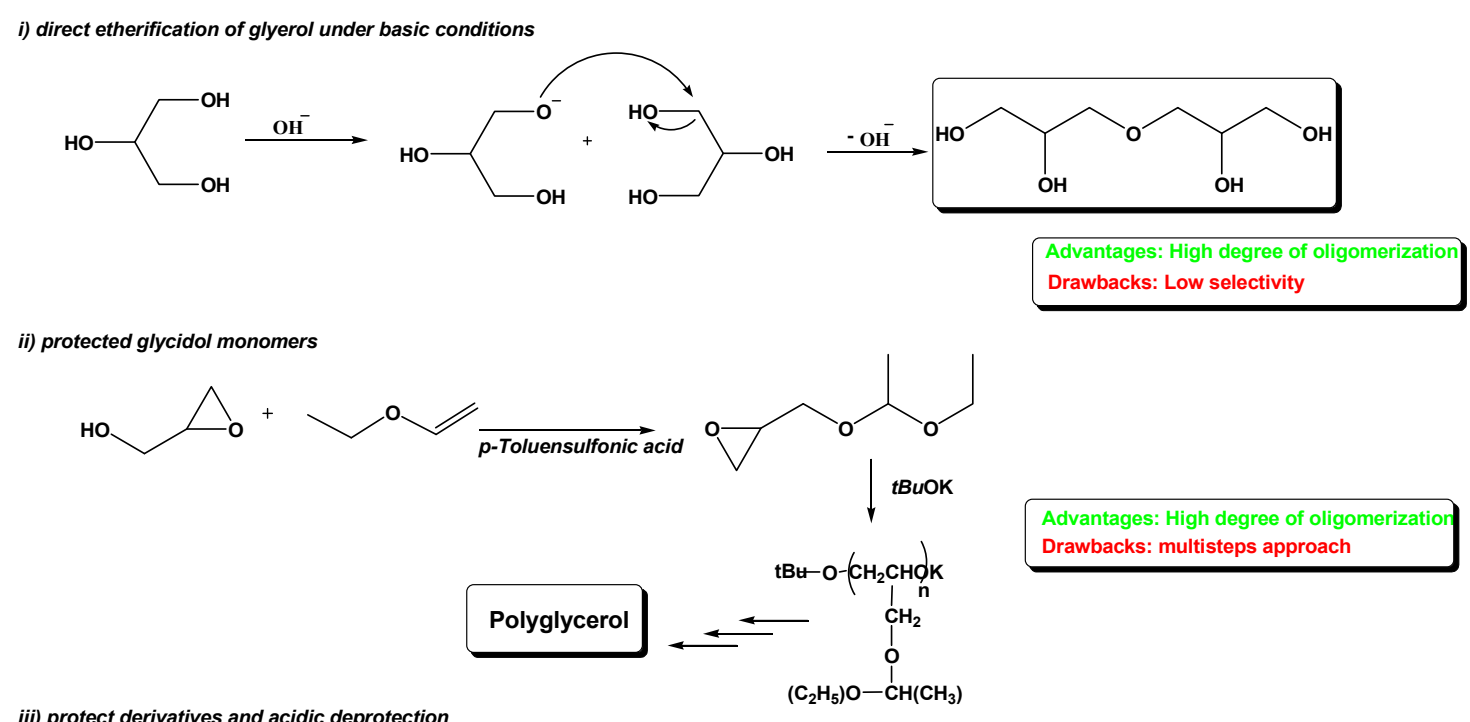

iii) protect derivatives and acidic deprotection<smiles>C(OC[C@H]1CO1)C1CO1</smiles><smiles>CC#CC</smiles>

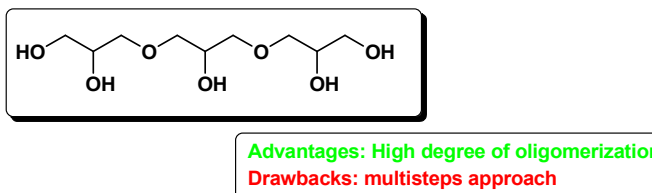

Chart 1. Literature examples for the preparation of polyglycerol.

The base-catalyzed direct etherification of glycerol (way 1) is recognized to be a fast but low selective reaction, yielding PGs (polyglycerols) with a high degree of oligomerization but with many secondary products. Intriguing alternatives make use of glycerol derivatives containing orthogonal protecting groups and oxirane functionalities that could allow an efficient and convergent synthesis (ways 2,3). However, despite the advantages of high oligomerization degrees, these approaches are complicated by multistep procedures that decrease the synthetic value, especially from the industrial standpoint.

However, the control of the linear selectivity in the polyetherification of glycerol remains an important challenge, which mainly depends on the catalyst properties.

Homogeneous catalysis processes are accomplished with strong acids such as sulfuric or benzenesulfonic acid under harsh conditions $\left(150-280^{\circ} \mathrm{C}\right.$ temperature range) that enable very fast but low selective polymerizations, leading to mixtures of cyclic and unsaturated acyclic compounds (alkenes, aldehydes, and ketones) [10]. Strong bases are also used as homogeneous catalysts, such as alkali hydroxides and carbonates, the latters being more active because of their higher solubility in glycerol [4,11]. For instance, high selectivity in linear diglycerol is obtained with $\mathrm{CsHCO}_{3}$ as a homogeneous catalyst, but at a low conversion of glycerol [12]. A significant increase of selectivity is observed with heterogeneous catalysts, especially using porous solid materials, which aims at exerting selective effects by reducing the abundant formation of cyclic isomers [1,13]. In this context, several studies reported the use of micro- and meso-porous acid zeolites with variable $\mathrm{Si} / \mathrm{Al}$ ratios, mesoporous aluminosilicates of the MCM-41 type, and acid-modified ion-exchange resins with a macroporous structure (Amberlist 16 and Amberlist 31) [13]. However, despite their efficiency, these materials still show unsatisfactory linear selectivities, because the reaction takes place with an $\mathrm{SN}^{1}$ mechanism leading to several undesired secondary and cyclic by-products [13].

Conversely, alkaline-earth metal oxides, such as $\mathrm{CaO}, \mathrm{SrO}$, and $\mathrm{BaO}$, display a superior aptitude in catalyzing the linear etherification of glycerol, affording di- and triglycerols with $80 \%$ of conversion after $20 \mathrm{~h}$ reaction at $220^{\circ} \mathrm{C}[14,15]$. Similar results are obtained with $\mathrm{Mg}-\mathrm{Al}$ mixed oxides but with lower conversions (50\%) [16]. However, due to the harsh conditions employed $\left(240-280{ }^{\circ} \mathrm{C}\right)$, 
these catalysts suffer from leaching problems that release alkaline cations from the solid surface, with the consequent inactivation and contamination of glycerol during the reaction [13]. For example, oxides of alkaline earth metals are partially leached during reaction, forming colloidal and/or transforming into a glyceroxide phase, which makes catalyst separation from reaction medium difficult [17].

To overcome these drawbacks and maintain the good catalytic performances of metal oxides, we envisioned to exploit rare earth elements. Amongst the most available of these compounds, the clean and cheap lanthanum oxide [4,17] has found a wide range of applications [18-20], comprising that to function as a catalyst for glycerol polymerization. Previous papers showed that a lanthanum-impregnated catalyst is the most active but the least selective, with glycerol dehydration to acrolein as the main side reaction [21].

Exploiting our experience in developing green synthetic methods [22,23], we envisioned that the catalytic performances of lanthanum oxide could be improved by anchoring on a robust and widely available support such as mesoporous silica gel KIT-6 [24]. We report here the synthesis, characterization, and catalytic performances of the hybrid material La(III)@KIT-6, which conjugates the amphoteric properties of the lanthanum oxide $[25,26]$, enabling a bifunctional catalysis, with the possibility of governing the selectivity of polymerization by means of mesoporous silica gel pores sizes $[17,21]$.

\section{Results and Discussion}

The catalyst was prepared by modifying a literature procedure, [24] by the impregnation of lanthanum nitrate onto mesoporous silica followed by calcination at $700{ }^{\circ} \mathrm{C}$ (Chart 2). The mesoporous structure was assured by means of a template $\left(\mathrm{P}_{123}\right)$, while a high ratio $\mathrm{LaNO}_{3} / \mathrm{mesSiO}_{2}(7 \mathrm{mmol} / 500 \mathrm{mg})$ was used to maximize the impregnation of rare earth on the support.

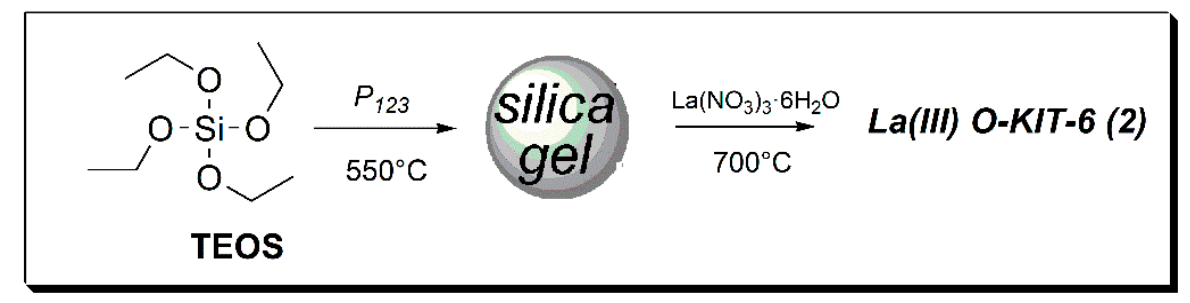

Chart 2. A schematic representation for the synthesis of catalyst (2).

\subsection{Characterization of Catalyst La(III)O-KIT-6 (2)}

The absorption of metal on silica gel was assured by several techniques. ATR-FTIR analyses of mesoporous silica gel KIT-6 [24] showed a broad band at 3400-3500 $\mathrm{cm}^{-1}$ that can be attributed to the stretching of $\mathrm{OH}$ bonds, while signals at 1223 to $1092 \mathrm{~cm}^{-1}$ are ascribed to the asymmetrical and symmetrical stretching of Si-O-Si. In addition, bands at $803 \mathrm{~cm}^{-1}$ denote the bending of an $\mathrm{Si}-\mathrm{O}$ framework in the structure (Figure 1A) [27]. The FTIR (Fourier transform infrared spectroscopy) spectrum of catalyst La(III)O-KIT-6 (2) calcined at $700{ }^{\circ} \mathrm{C}$ displayed new signals at $644 \mathrm{~cm}^{-1}$, which can be attributed to the $\mathrm{La}-\mathrm{O}$ bond, together with 1505 and $1466 \mathrm{~cm}^{-1}$, that could be assigned to the asymmetric stretching mode of $\mathrm{CO}_{3}{ }^{-2}$ groups in $\mathrm{La}-\mathrm{CO}_{3}$ - (Figure 1B) $[25,28]$. 

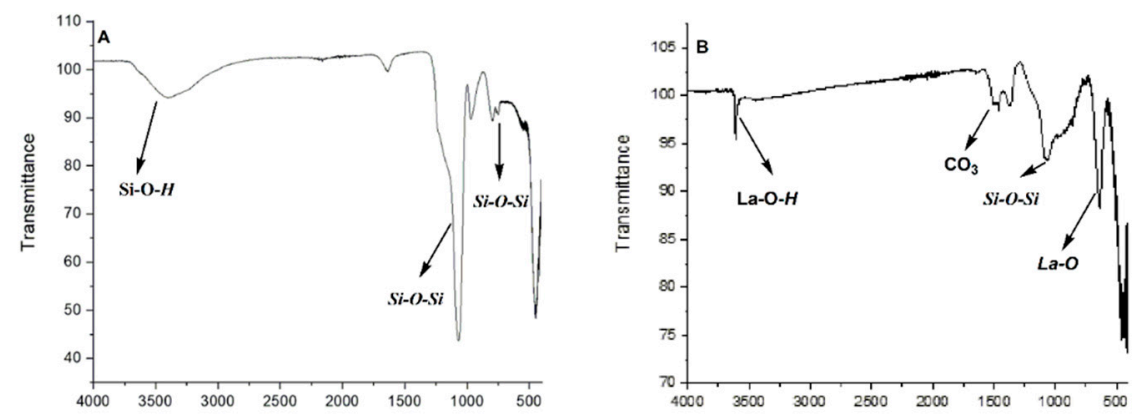

Figure 1. ATR-FTIR (Attenuated total reflection-Fourier transform infrared spectroscopy) spectra of (A) KIT-6 and (B) catalyst La(III)O-KIT-6 (2).

After the reaction, catalyst (2) was brown; then, it was washed several times with methanol and was again calcined at $700{ }^{\circ} \mathrm{C}$ and reused for a new cycle. After three cycles, the catalyst continued to show the signals of $\mathrm{CO}_{3}{ }^{-2}$, while an intensity of the bands of $\mathrm{La}-\mathrm{OH}$ and $\mathrm{La}-\mathrm{O}$ lower than the fresh catalyst (2) was obtained (Figure 2).

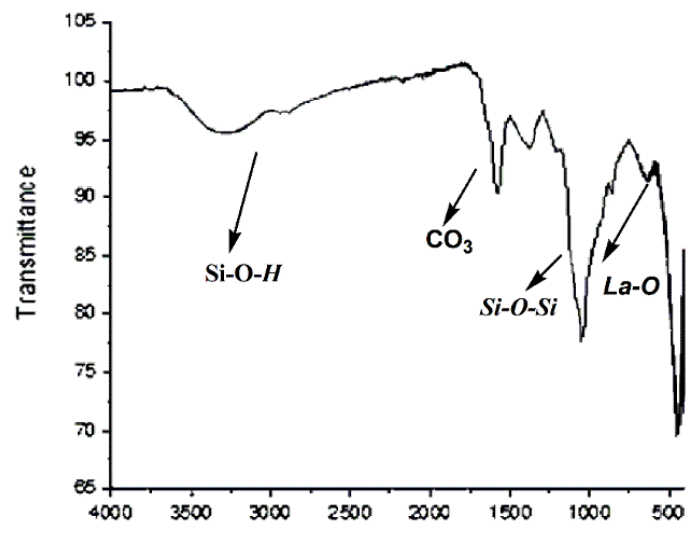

Figure 2. ATR-FTIR spectra of La(III)O-KIT-6 after three cycles of reaction.

The XPS (X-ray photoelectron spectroscopy) spectrum of support (Figure 3, left) showed the expected main components, $\mathrm{Si}$ and $\mathrm{O}$, with a little $\mathrm{C}$ contamination (ca. 5 at. \%). Instead, the spectrum of the catalyst (2) was dominated by the peaks of lanthanum (Figure 3, right), indicating that the rare earth was successfully supported onto the mesoporous silica. Indeed, peaks ascribed to Si were still present, although with reduced intensity. More specifically, the Si2p signal overlapped with that of La4d, becoming no longer diagnostic, while the Si2s peak was still clearly visible.
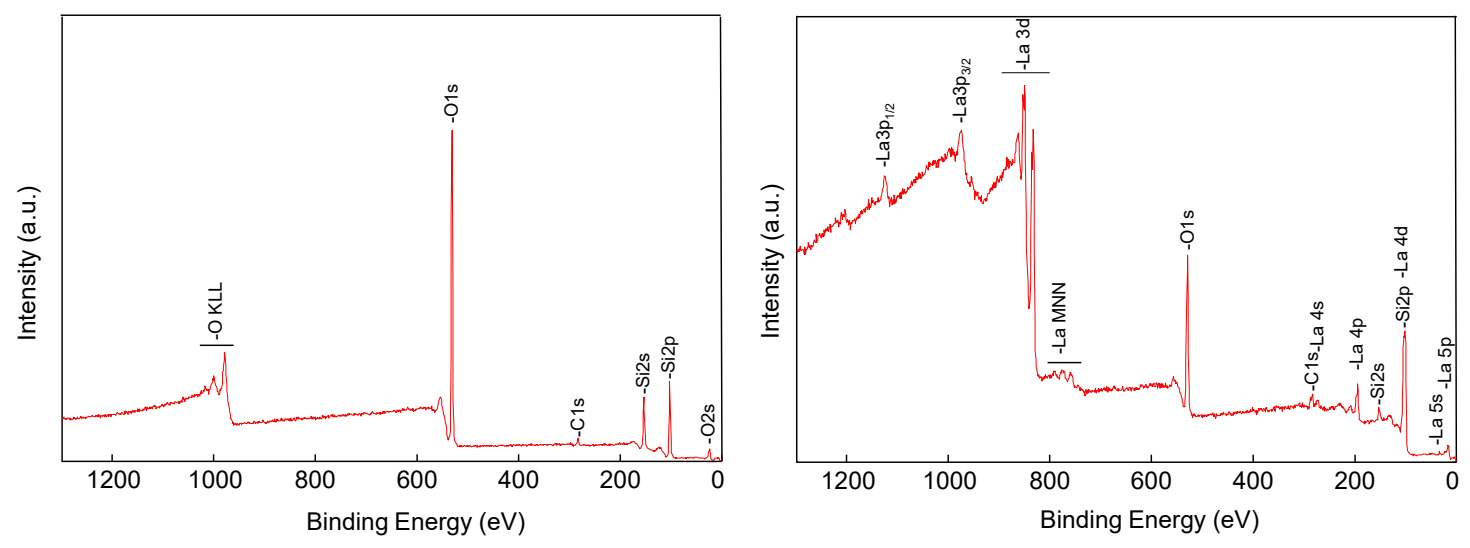

Figure 3. Survey spectra of mesoporous silica KIT-6 (left) and La(III)O-KIT-6 catalyst (2) (right). 
The elemental composition of support of catalyst (2), as determined by XPS peaks integration (Table 1), was clearly characterized by the presence of lanthanum(III) in accordance with the literature [28,29], while the presence of carbon can be attributed to the $\mathrm{CO}_{3}{ }^{-2}$ group, confirming that lanthanum is present both as $\mathrm{La}(\mathrm{OH})_{3}$ and as $\mathrm{LaO}_{2} \mathrm{CO}_{3}[30,31]$. The component of carbon is increased in the reused catalyst after three times, due to the absorption of the oligomer on its surface, as well as the formation of $\mathrm{La}_{2} \mathrm{O}_{2} \mathrm{CO}_{3}$ (see Supplementary Materials Figure S1). Meanwhile, the quantity of lanthanum is practically the same, confirming that the catalyst does not undergo leaching (Supplementary Materials Figure S2).

Table 1. Elemental composition of (a) support KIT-6, (b) catalyst (2), and (c) catalyst (2) after the 3rd recycle.

\begin{tabular}{cccc}
\hline Elements & KIT-6 & La(III)O-KIT-6 & $\begin{array}{c}\text { La(III)-O-KIT-6 } \\
\text { After 3 Cycles of Reaction }\end{array}$ \\
\hline $\mathrm{O}$ & $66.5 \%$ & $62.8 \%$ & $59.3 \%$ \\
$\mathrm{Si}$ & $28.7 \%$ & $10.7 \%$ & $10.4 \%$ \\
$\mathrm{C}$ & $4.8 \%$ & $14.9 \%$ & $20.2 \%$ \\
$\mathrm{La}$ & - & $11.6 \%$ & $10.1 \%$ \\
\hline
\end{tabular}

Figure 4 shows a comparison of the high-resolution La3 $\mathrm{d}_{5 / 2}$ spectra of catalyst before and after three cycles. The La3d region has well separated spin-orbit components, which were each further split by multiplet splitting. The magnitude of the multiplet splitting and intensity ratio of each multiplet-split component are chemically diagnostic [29]. Both spectra of Figure 4 show a peak separation of nearly $3.8 \mathrm{eV}$, which is indicative of the presence of $\mathrm{La}(\mathrm{OH})_{3}$. However, comparing these two spectra with that of pure $\mathrm{La}(\mathrm{OH})_{3}$ reported in the literature, a pronounced valley between the multiplet-split components is observed, which could be indicative of the presence of two compounds, one of which is a lanthanum dioxycarbonate $\mathrm{La}_{2} \mathrm{O}_{2} \mathrm{CO}_{3}[29,31]$.

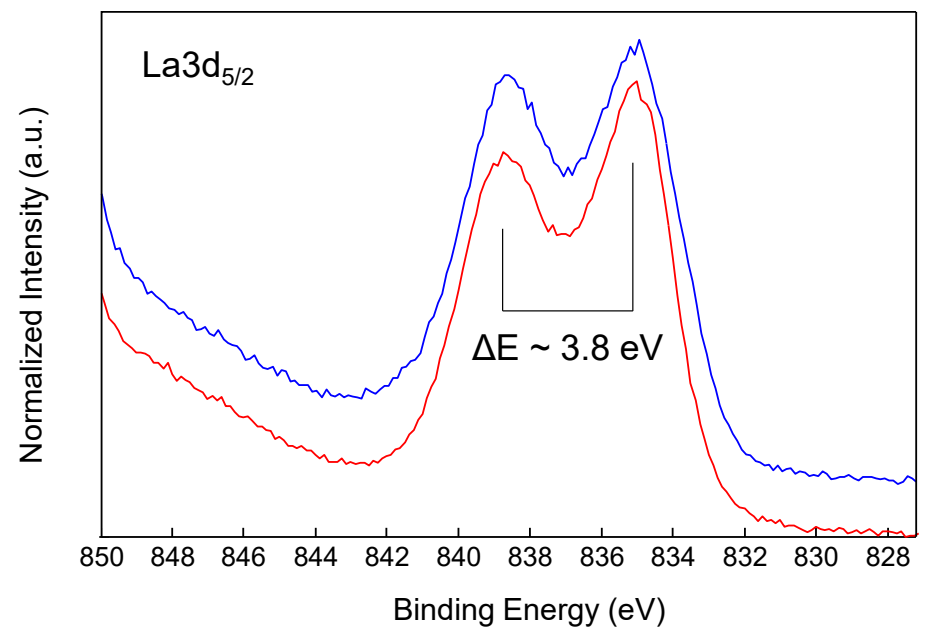

Figure 4. High-resolution La3d $\mathrm{d}_{5 / 2}$ spectra of La(III)O-KIT-6 (red) and La(III)O-KIT-6 after three cycles of reaction (blue).

These conclusions were confirmed by powder X-ray diffraction (PXRD) spectra, where the broad amorphous halo in the $2 \Theta$ range $20-30^{\circ}$ confirms the formation of amorphous silica under the chosen experimental conditions (Figure 5a). The reaction of $\mathrm{La}\left(\mathrm{NO}_{3}\right)_{3} \cdot 6 \mathrm{H}_{2} \mathrm{O}$ with citric acid in the presence of amorphous silica in solution, followed by calcination at $700{ }^{\circ} \mathrm{C}$, brought about the formation of two crystalline La-phases, which are lanthanum oxycarbonate (monoclinic and hexagonal phase) (major compound) $[30,31]$ and lanthanum hydroxide $\mathrm{La}(\mathrm{OH})_{3}$ (hexagonal phase) (Figure 5, trace b) $[27,29]$. Both crystalline phases cover entirely the amorphous $\mathrm{SiO}_{2}$ phase, which is confirmed by the absence of 
the characteristic broad hump for amorphous $\mathrm{SiO}_{2}$ in trace b [30]. The PXRD spectrum of the recovered catalyst (Figure 5, trace c) shows the typical XRD pattern for lanthanium oxycarbonate, which is indeed the only crystalline phase on the $\mathrm{SiO}_{2}$-based support as in trace b, in accordance with FTIR analysis.

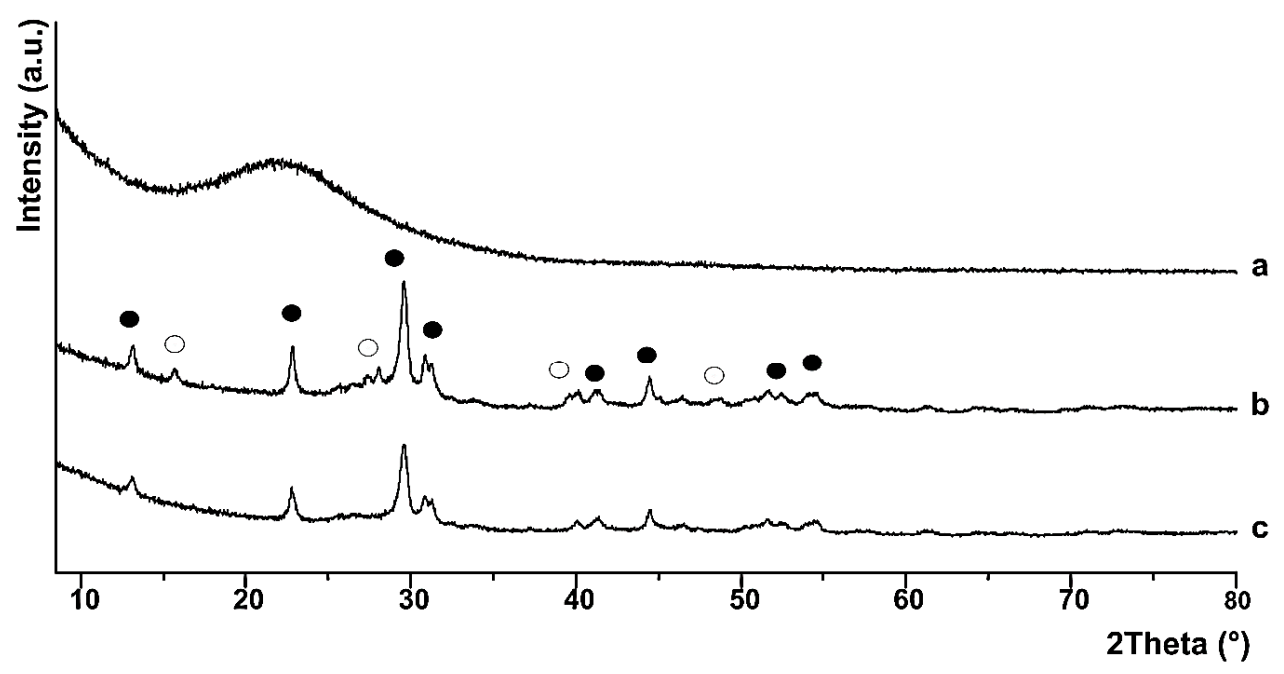

Figure 5. Powder X-ray diffraction (PXRD) spectra for KIT-6 (a), La(III)O-KIT-6 (2) (b), and La(III)O-KIT-6 after III cycle $\left(2^{\prime}\right)$ (c). Full circles denote $\mathrm{La}_{2} \mathrm{O}_{2} \mathrm{CO}_{3}$ and empty circles denote $\mathrm{La}(\mathrm{OH})_{3}$.

To evaluate the specific surface area and pore sizes distribution, Brunauer-Emmett-Teller (BET) and Barrett-Joyner-Halenda (BJH) methods were used, respectively. $\mathrm{N}_{2}$ adsorption-desorption isotherms (see Figures S3-S5 in Supplemental Materials) show a hysteresis located in the relative pressure range of 0.5-1.0, which is characteristic of mesoporous materials [24], and Table 2 shows the specific surface area of both the support and catalyst. The BET surface area, the BJH pore size, and the pore volume of the mesoporous silica KIT- 6 are in accord with the literature [24]. The presence of lanthanum oxide on pore surfaces is confirmed by the decrease of all these three parameters in catalyst 2. In addition, the decrease of the pore sizes is due to the acid/base interactions between the lanthanum oxide, which is formed during the calcination, and the silanol groups $(\mathrm{Si}-\mathrm{OH})$ of the mesoporous silica surface (see the full spectra for BET analysis Figures S3-S5 in the Supplemental Materials) [17].

Table 2. The pore structure parameters of the as-prepared mesoporous silica KIT-6 and the catalyst before and after the etherification of glycerol.

\begin{tabular}{cccc}
\hline Sample & BET Surface Area $\left(\mathbf{m}^{\mathbf{2}} \cdot \mathbf{g}^{\mathbf{- 1}}\right)$ & BJH Pore Size $(\mathbf{n m})$ & Pore Volume $\left(\mathbf{c m}^{\mathbf{3}} \cdot \mathbf{g}^{-\mathbf{1}}\right)$ \\
\hline KIT-6 & $1003 \pm 11$ & $2.9 \pm 0.6$ & $1.3 \pm 0.4$ \\
La(III)O-KIT-6 (2) & $69.1 \pm 0.3$ & $2.4 \pm 0.4$ & $0.32 \pm 0.04$ \\
La(III)O-KIT-6 & $66.7 \pm 0.4$ & $1.7 \pm 0.3$ & $0.20 \pm 0.05$ \\
after III cycle $\left(\mathbf{2}^{\prime}\right)$ & & & \\
\hline
\end{tabular}

As expected, after three cycles, a further decrease of the pore sizes is observed, due to the effect of calcinations at $700{ }^{\circ} \mathrm{C}$ during the recycling process to eliminate the organic phase, as shown by the XPS analysis, and thanks to the adsorption of organic material in the exhausted catalyst. (See Figure S1 C1s spectra for the catalyst La(III)OKIT-6 before (A) and after (B) three recycling experiments in Supplementary Materials)

Further confirmations of the change in the morphology of the catalyst were given by the SEM (scanning electron microscope) analyses. The SEM image of catalyst La(III) O-KIT-6 (2) shows the presence of pores, while the distribution of lanthanum on silica is homogeneous, as shown by the purple color in Figure 6 (see also the Supplementary Materials Figure S6-S8 for the complete analysis). 

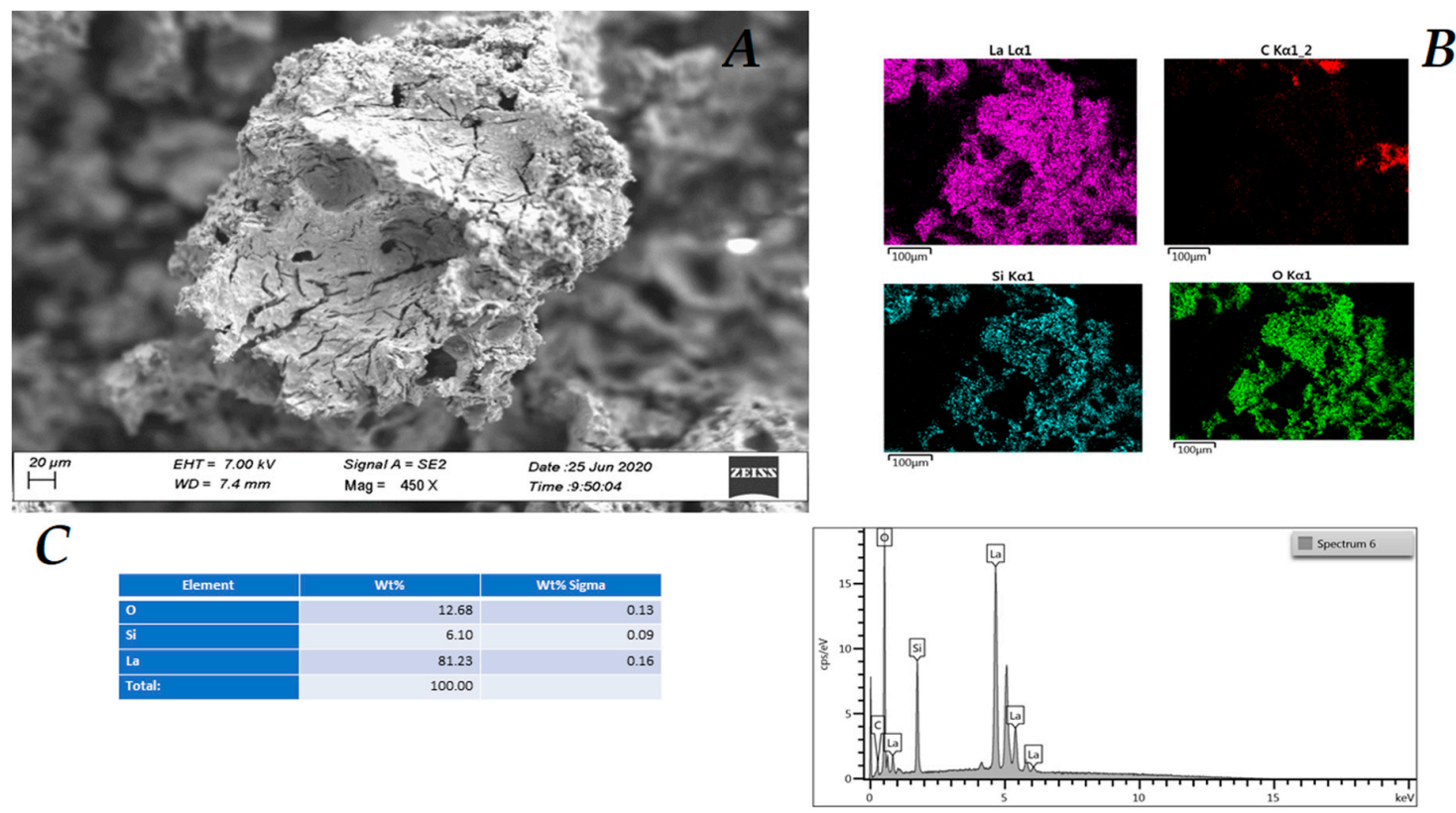

Figure 6. La(III) O-KIT-6 (2). (A) SEM (scanning electron microscope) image at $20 \mu \mathrm{m}$; (B) maps of elements, (C) EDS (energy dispersive X-ray analysis) analysis and composition.

After the third cycle, EDS (energy dispersive X-ray analysis) analysis (insert C, Figure 7) shows that the chemical composition of the catalyst (2) does not change significantly, which is also in agreement with the XPS analysis, while its morphology undergoes evident changes, in particular its surface roughness (Figure 7A and Supplementary Materials Figures S9 and S10).
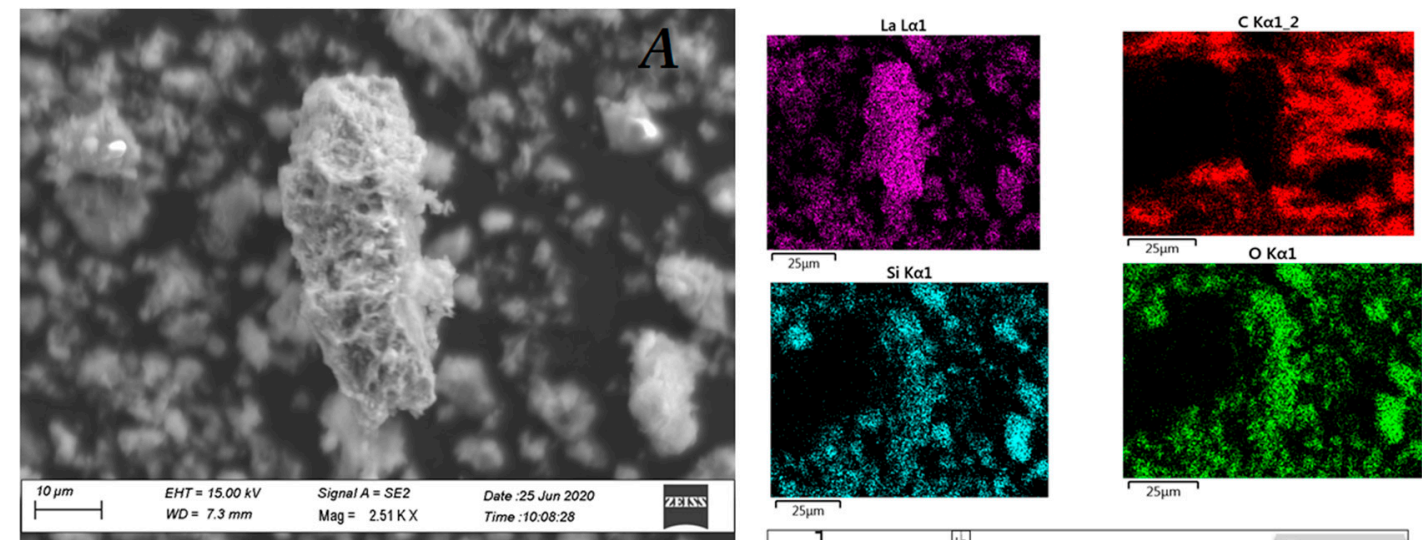

C
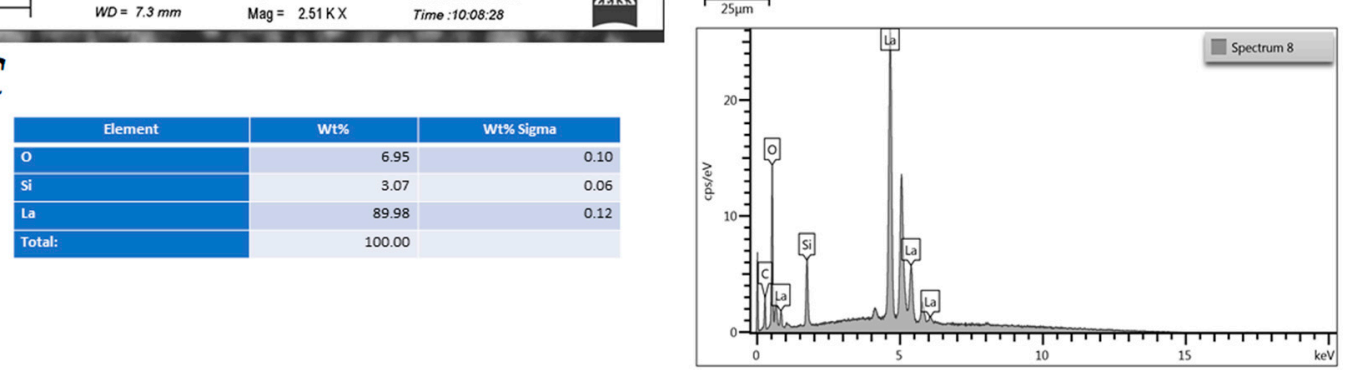

Figure 7. La(III) O-KIT-6 (2') after three reaction cycles (A) SEM image at $10 \mu \mathrm{m}$; (B) maps of elements, (C) EDS analysis and composition. 


\subsection{Catalytic Tests}

According to most of the reported procedures (see Table 3), catalytic experiments were conducted in a batch, at $240^{\circ} \mathrm{C}$ and under solvent-free conditions, in the presence of $2 \% w / w$ of catalyst (2) (see Table 3). Glycerol conversions were evaluated by GC/MS after derivatization (see the Experimental section for the complete procedure), HPLC analyses, and monitoring of the water amounts produced during reaction by means of a Dean-Stark apparatus (see the experimental section) $[32,33]$. The identification of linear (3-5) and cyclic $\left(4^{\prime}, 5^{\prime}, 5^{\prime \prime}\right)$ glycerol oligomers listed in Scheme 1 was accomplished by the HPLC-IT-TOF technique, and the spectra obtained are in accordance with the literature $[10,34-36]$ and the NIST DATA BASE for EI mode.

Table 3. Comparison of efficiency of heterogeneous catalyst in glycerol linear oligomerization. ${ }^{1}$<smiles>OCC(O)CO</smiles>

(1)

$$
\underset{\mathrm{T}=220-260^{\circ} \mathrm{C}}{\stackrel{\text { catalyst }(2 \% \mathrm{w} / \mathrm{w})}{\longrightarrow}}
$$<smiles>OCC(O)CO[TeH]</smiles>

(3) $\mathrm{n}=2$

(4) $n=3$

(5) $n=4$

\begin{tabular}{|c|c|c|c|c|c|c|c|c|}
\hline \multirow[b]{2}{*}{ Run } & \multirow{2}{*}{$\begin{array}{l}\text { Heterogeneous } \\
\text { Catalysts }\end{array}$} & \multirow{2}{*}{$\begin{array}{l}\text { Temp. } \\
\left({ }^{\circ} \mathrm{C}\right)\end{array}$} & \multirow{2}{*}{$\underset{\%}{\text { Conv. }}$} & \multicolumn{3}{|c|}{ Selectivity (\%) ${ }^{2}$} & \multirow{2}{*}{ Re-use } & \multirow{2}{*}{ Ref. \# } \\
\hline & & & & $\begin{array}{l}\text { Dimer } \\
\text { (3) }\end{array}$ & $\begin{array}{l}\text { Trimer } \\
\text { (4) }\end{array}$ & $\begin{array}{l}\text { Tetramer } \\
\text { (5) }\end{array}$ & & \\
\hline 1 & La(III) O-KIT-6 (2) & 240 & 72 & 32 & 22 & 42 & & This work \\
\hline 2 & $\mathrm{CaO}$ & 220 & 80 & 60 & 40 & & none & 14 \\
\hline 3 & $\mathrm{Mg} / \mathrm{Al}$ mixed oxides & 220 & 51 & 43 & 10 & - & none & 16 \\
\hline 4 & Cs-MCM-41 & 260 & 40 & 90 & 10 & - & yes & 21 \\
\hline 5 & $\begin{array}{l}\text { Lanthanum } \\
\text { MCM- } 41^{3}\end{array}$ & 260 & 94 & 26 & 23 & 27 & none & 17 \\
\hline 6 & KIT-6 & 240 & 23 & 92 & 0 & & & \\
\hline
\end{tabular}

${ }^{1}$ General reaction conditions: glycerol 1 (54 mmol), catalyst $2 \%(w / w)$ heated at the proper temperature under solvent-free conditions for $22-24 \mathrm{~h} .{ }^{2}$ Determined by HPLC (see experimental section and Supplementary Materials Figure S11). ${ }^{3}$ Acrolein and oxidation by-products are formed.

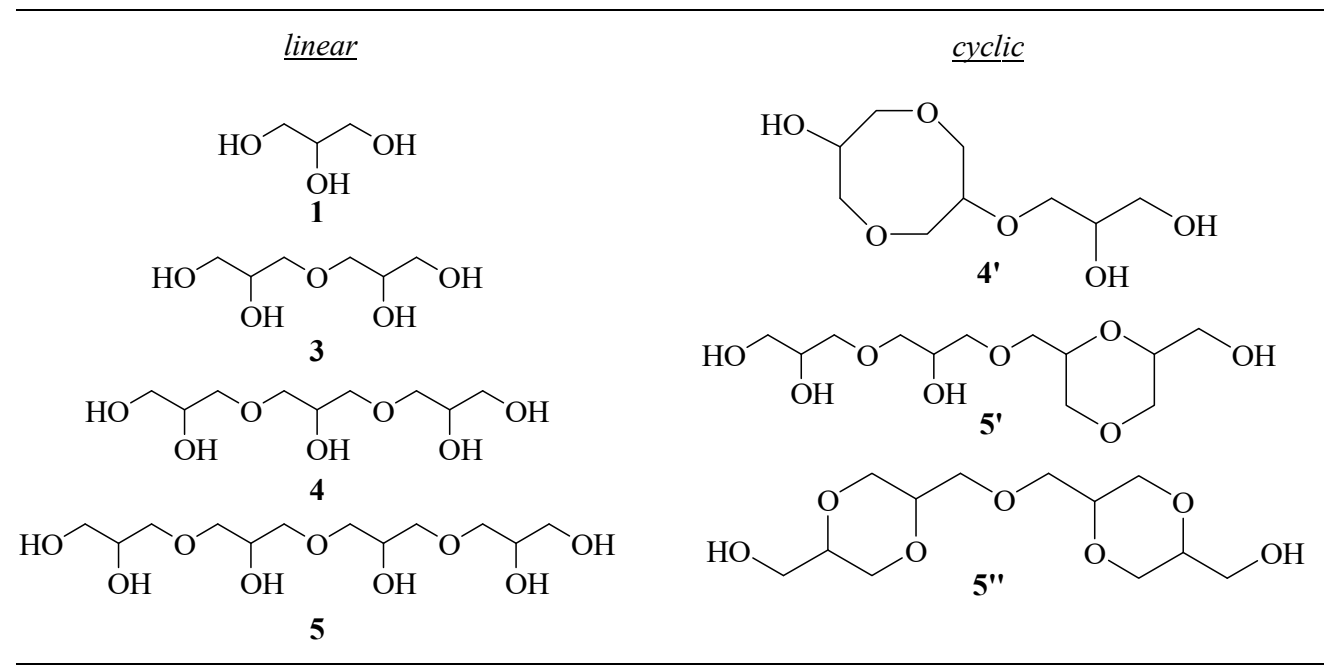

Scheme 1. Linear and cyclic oligomers obtained during glycerol etherification with (2).

Catalyst efficiency was evaluated monitoring oligomerization products in the range of $24 \mathrm{~h}$ (Figure 8). A survey of this screening clearly indicated that the oligomerization promoted by catalyst 2 , within the time range investigated, lead to good yields (about $40 \%$ ) of linear tetramer 5 and in general of linear oligomers (about $96 \%$, Table 3, entry 1) without the formation of oxidation and dehydration 
by-products, which is a result representing a significant improvement if compared with the recent literature (see Table 3).

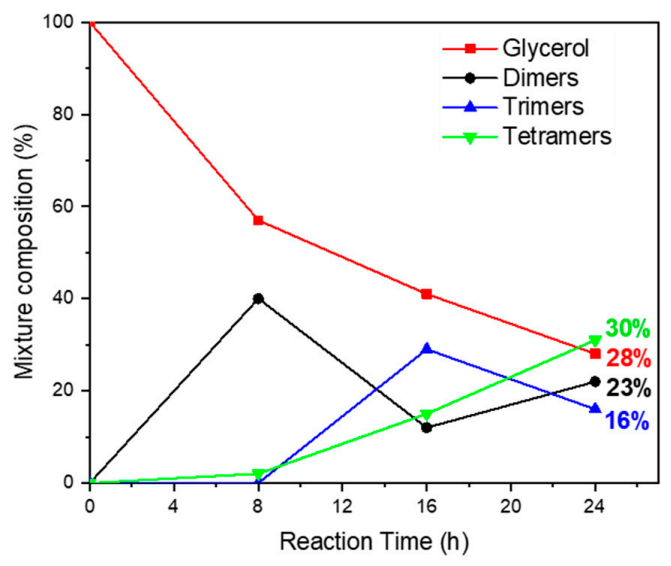

Figure 8. Composition of reaction mixture vs. reaction time.

A careful analysis of trend over time shows that after $8 \mathrm{~h}$, a good conversion in diglycerol (3) is accompanied by trace amounts of trimer (4) and a small but interesting percentage (4\%) of linear tetramer 5, which is indicative that at the beginning of the process, surely due to the influence of support, dimer (3) undergoes more rapidly a dimerization reaction rather than a chain prolonging the reaction with glycerol.

This result could be rationalized by assuming that the mesoporous structure of support, due to the pore sizes, would allow hosting dimer (3) in the cavity enabling mainly its linear homocoupling. Subsequently, the formation of trimer (4) becomes rapid, reaching the maximum yield in $16 \mathrm{~h}$, after which the formation of tetramer (5) becomes dominant. After $24 \mathrm{~h}$, glycerol conversion reached $72 \%$, with a selectivity toward a linear tetramer (5) of $42 \%$, followed by $32 \%$ of dimer (3), $22 \%$ of trimer (4), and $4 \%$ of cyclic oligomers.

To support our hypothesis, we determined the dimension of linear tetramer 5 and the corresponding cyclic compound 5". Figure 9 shows that cyclic tetramer possess a diameter roughly twice that of linear isomer, which is a condition that can cause difficulty accommodating into the pores of the catalyst.
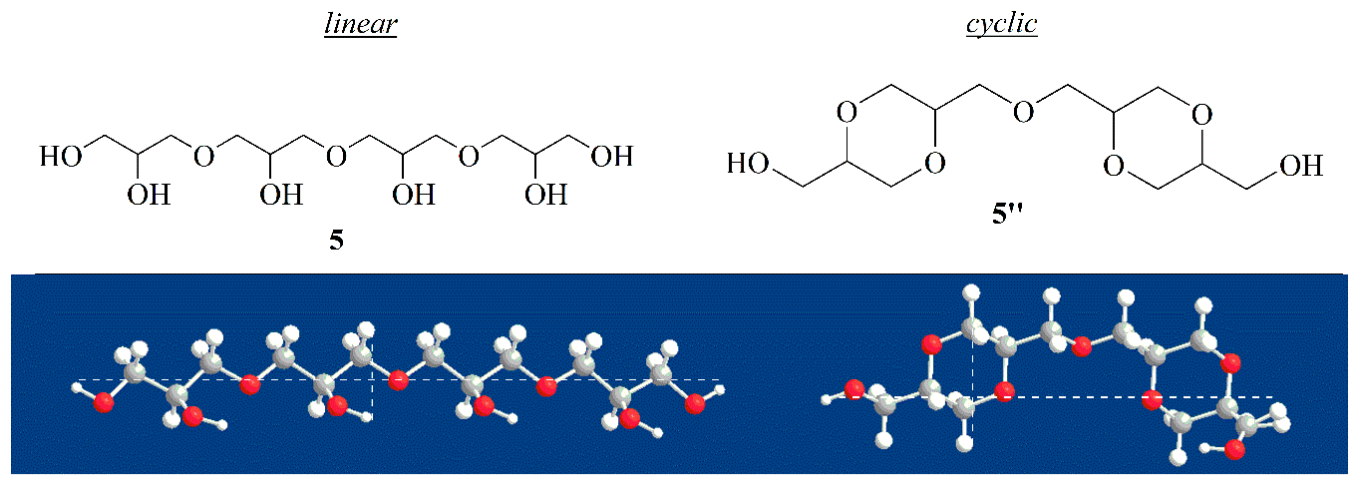

2. $12 \mathrm{~nm} ; 0.29 \mathrm{~nm}$

$1.43 \mathrm{~nm} ; 0.55 \mathrm{~nm}$

Figure 9. Determination of dimensions for tetramer 5 and 5" with Chem3D.

Neither alkenes nor oxidation by-products were observed during the range time investigated.

All these data show that catalyst 2 is efficient in giving essentially the formation of linear polyglycerol. Table 3 compares catalytic performances of our catalyst La(III)OKIT-6 (2) (run 1) with those of some analogous heterogeneous catalysts reported in the literature. Data in the table clearly 
highlight the better activity of 2 in giving higher yields and longer linear oligomers with respect to the basic oxides $\mathrm{CaO}$ and $\mathrm{MgO}$ (runs 2-3). Likewise, better performances of support silica gel KIT-6 are observed compared with the most used mesoporous material MCM-41 (runs 4-5). In this latter case, dehydration or oxidation by-products such as acrolein are formed during the reaction (run 5). A further advantage of using rare earth metal oxides as catalysts originates from an easy separation of the catalyst achieved by centrifugation of the suspension and washing of the catalytic material with methanol.

Finally, a blank reaction with silica gel support KIT-6 affording very low glycerol conversion to dimer (3) and trimer (4) indicates that lanthanum oxide is a true catalyst for this process (run 6).

A plausible explanation of the efficiency of catalyst (2) in the etherification could be found in the amphoteric properties of lanthanum oxide derivatives, through which a bifunctional catalysis phenomenon can be invoked. In particular, as reported in Figure 10, the basic sites of 2, represented by oxygen atoms linked to lanthanum catalyst, should provide de-protonation of hydroxyl groups of glycerol, thus creating alcoholate functionalities. Simultaneously, the Lewis acid sites, represented by lanthanum, should coordinate glycerol $\mathrm{OH}$ groups, favoring the condensation reaction (i.e., elimination of water) (Figure 10) [14,25].

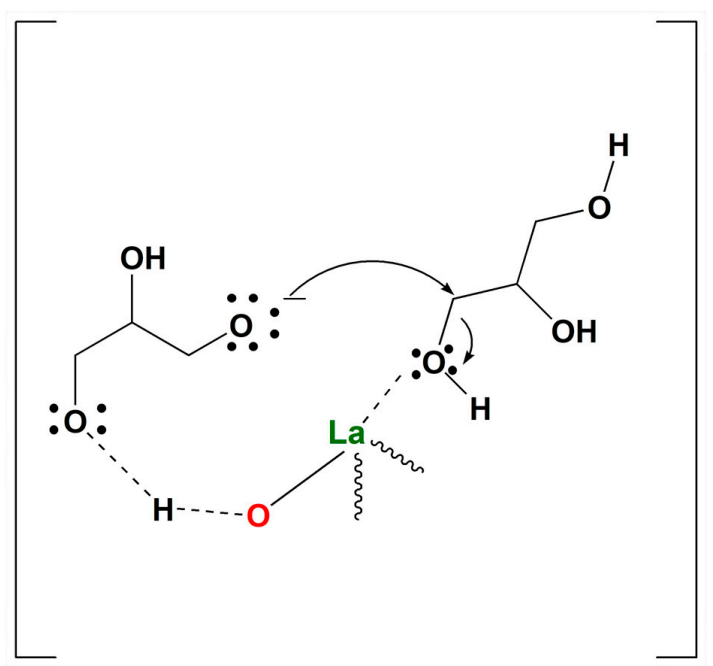

Figure 10. Scheme of bifunctional catalysis of lanthanum in catalyst (2).

In addition, the mesoporous structure of the support, due to the pore sizes, should be suitable for the accommodation of linear oligomers, thus enhancing the linear selectivity.

\subsection{Catalysts Recycle}

Catalyst 2 was recycled three times, under optimized conditions. After each run, it was washed with methanol and calcinated at $700{ }^{\circ} \mathrm{C}$ to remove the organic phase. In the second and third runs, conversion gradually decreased, while selectivity favored only diglycerol (3) and triglycerol (4). (Table 4)

Table 4. Recycle of catalyst $2 .^{1}$

\begin{tabular}{ccccc}
\hline Cycles & $\begin{array}{c}\text { Conv } \\
\text { \% }\end{array}$ & $\begin{array}{c}\text { Diglycerol } \\
\text { (3) } \%\end{array}$ & $\begin{array}{c}\text { Triglycerol } \\
\mathbf{( 4 )} \%\end{array}$ & $\begin{array}{c}\text { Tetraglycerol } \\
\text { (5) } \%\end{array}$ \\
\hline 1 & 72 & 30 & 20 & 42 \\
2 & 55 & 58 & 42 & \\
3 & 25 & 64 & 36 & \\
\hline
\end{tabular}

${ }^{1}$ Reactions were monitored using GC/MS analysis (see experimental section and Supplementary Materials Figures S12-S14). 
A plausible explanation of these results could be given assuming that the decrease of pore sizes and rugosity of support, due to catalyst reactivation (by calcination), slows down etherification, which is thought to occur mainly inside them privileging, for steric reasons, the formation of linear oligomers.

\subsection{Oligomers Identification}

Glycerol oligomers obtained from the catalytic test were identified using HPLC chromatography coupled with ESI-IT-TOF-HR-MS technique (C18 Supelcosil column), exploiting similar studies reported in the literature [10,34,35]. Figure 11 and Table 5 report ESI(+)-HR-Mass spectra and the peaks assignment of major products, respectively [35-37].

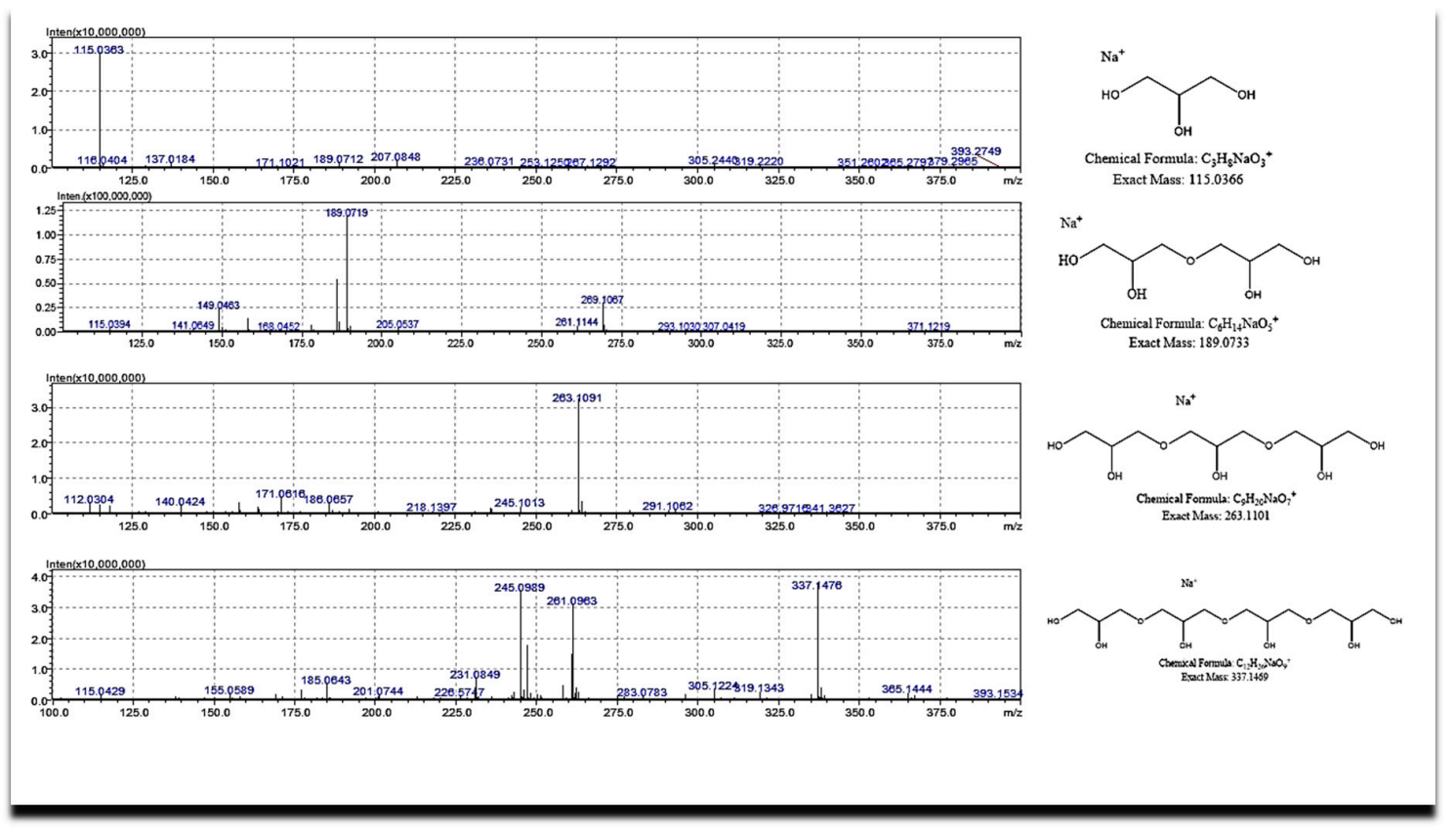

Figure 11. ESI(+)-MS of oligomers obtain from the etherification of glycerol.

Table 5. Principal fragmentation pathways of linear polyglycerols.

\begin{tabular}{|c|c|c|c|}
\hline Oligomers & $\begin{array}{l}\text { Chemical Formula/ } \\
\text { Exact Mass }\end{array}$ & \multicolumn{2}{|c|}{ Principal Fragmentation Pathways } \\
\hline \multirow[t]{4}{*}{ Diglycerol (3) ${ }^{1}$} & $\mathrm{C}_{6} \mathrm{H}_{14} \mathrm{NaO}_{5}{ }^{+} / 189.0733$ & 189.0719 & $\left(\right.$ Diglycerol $\left.\mathrm{Na}^{+}\right)$ \\
\hline & & 168.0452 & (Diglycerol 2H $\mathrm{H}^{+}$) \\
\hline & & 149.0463 & (Diglycerol $\left.\mathrm{H}^{+}\right)-\mathrm{H}_{2} \mathrm{O}$ \\
\hline & & 115.0369 & Diglycerol $\left.\mathrm{Na}^{+}\right)-\mathrm{C}_{3} \mathrm{H}_{6} \mathrm{O}_{2}$ \\
\hline \multirow[t]{3}{*}{ Triglycerol (4) } & $\mathrm{C}_{9} \mathrm{H}_{20} \mathrm{NaO}_{7}^{+} / 263.1101$ & 263.1091 & (Triglycerol $\mathrm{Na}^{+}$) \\
\hline & & 245.1013 & (Triglycerol $\left.\mathrm{Na}^{+}\right)-\mathrm{H}_{2} \mathrm{O}$ \\
\hline & & 171.0616 & $\left(\right.$ Triglycerol $\left.\mathrm{Na}^{+}\right)-\mathrm{C}_{3} \mathrm{H}_{8} \mathrm{O}_{3}$ \\
\hline \multirow[t]{5}{*}{ Tetraglycerol (5) } & $\mathrm{C}_{12} \mathrm{H}_{26} \mathrm{NaO}_{9}{ }^{+} / 337.1469$ & 337.1476 & (Tetraglycerol $\mathrm{Na}^{+}$) \\
\hline & & 319.1343 & $\left(\right.$ Tetraglycerol $\left.\mathrm{Na}^{+}\right)-\mathrm{H}_{2} \mathrm{O}$ \\
\hline & & 305.1224 & (Tetraglycerol $\mathrm{Na}^{+}$)-2 $\mathrm{H}_{2} \mathrm{O}$ \\
\hline & & 261.0693 & (Tetraglycerol Na$\left.{ }^{+}\right)-\mathrm{C}_{3} \mathrm{H}_{8} \mathrm{O}_{2}+2$ \\
\hline & & 245.1013 & (Tetraglycerol $\left.\mathrm{Na}^{+}\right)-\mathrm{C}_{3} \mathrm{H}_{8} \mathrm{O}_{3}$ \\
\hline
\end{tabular}

${ }^{1}$ See also Supplementary Materials Figure S15 for hybrid oligomers.

In addition, dimer and trimer were also investigated by GC-MS analyses of silanized [38] products in EI mode (70 eV), confirming the linear structure of the oligomers (Figure 12). 

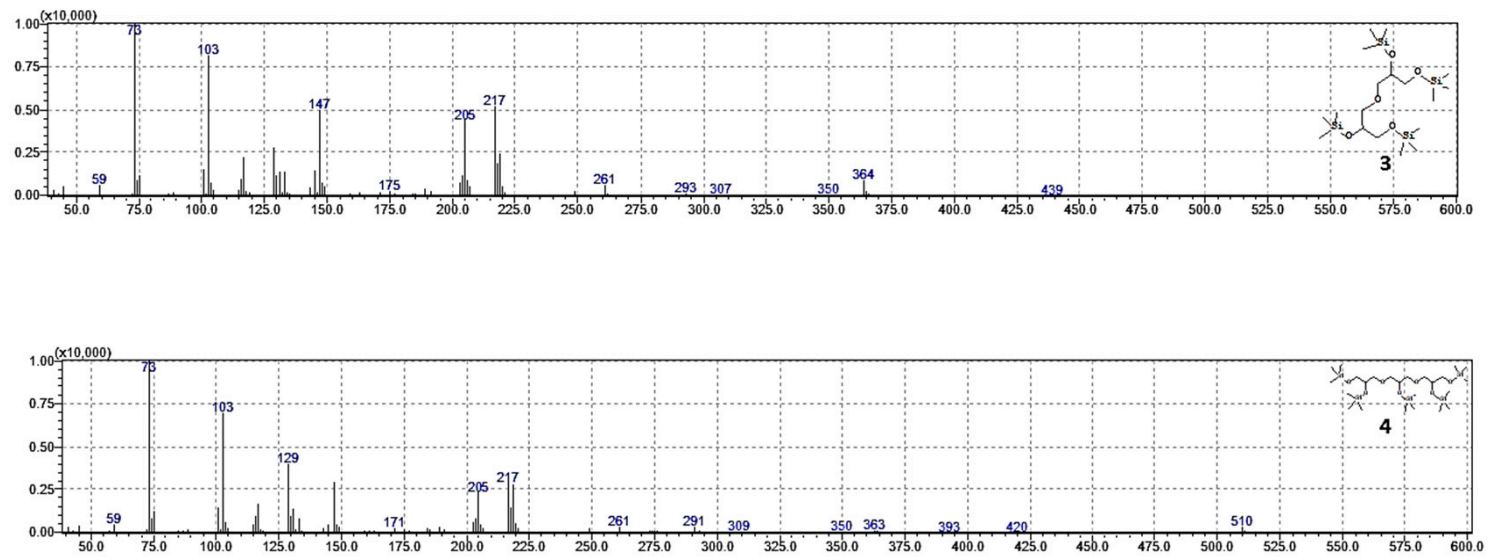

Figure 12. Mass spectra of dimer (3) and trimer (4) in EI mode.

A further confirmation of the presence of linear polymerization products is given by the NMR analysis, which shows, as reported in Figure 13, only the typical chemical shifts of linear oligomers in the 60-75 ppm zone [9] (see also the Supplemental Materials for complete NMR analysis).

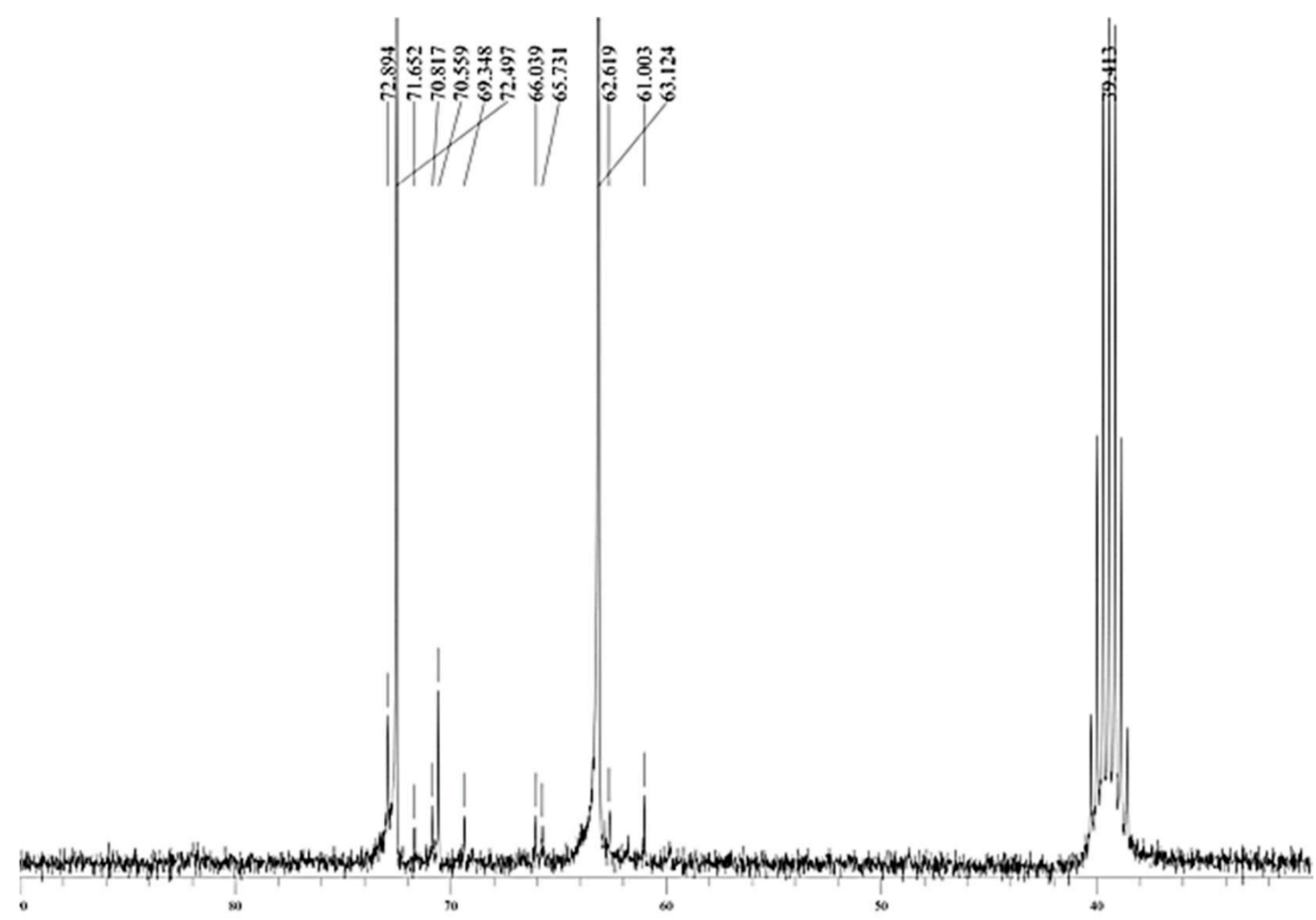

Figure 13. Spectrum ${ }^{13} \mathrm{C}-\mathrm{NMR}(75 \mathrm{MHz}$ DMSO-d6) of mixture of reaction at $24 \mathrm{~h}$ in the range $30-90 \mathrm{ppm}$.

\section{Materials and Methods}

Surfactant $\mathrm{P}_{123}, \mathrm{n}$-butanol, $\mathrm{HCl}$ (37 wt \%), tetraethylorthosilicate (TEOS), lanthanum nitrate hexahydrate $\left(\mathrm{La}\left(\mathrm{NO}_{3}\right)_{3} \cdot 6 \mathrm{H}_{2} \mathrm{O}\right)$, ethanol, citric acid, methanol, and water $\mathrm{LC} / \mathrm{MS}$ degree were purchased from Sigma-Aldrich, (MERCK, MI, Italy) and used as received, without any further treatment. Glycerol resulting from FAMEs synthesis was gift of Greenswitch industry (MT; Matera, Italy).

GC/MS analyses were run on a Shimadzu GLC 17-A instrument (Shimadzu, MI, Italy) connected with a Shimadzu QP5050A selective mass detector (Shimadzu, MI, Italy) using a SLB-5MS column $(30 \mathrm{~m} \times 0.25 \mathrm{~mm}$ id, film thickness $0.25 \mu \mathrm{m})$. Mass spectra were performed in EI mode $(70 \mathrm{eV})$, 
and conversions were determined using 2,5-dimethylanisole as an external standard. The identification of glycerol oligomers and determination of selectivities were performed by HPLC with a C18 Column Supelcosil ( $15 \mathrm{~cm} \times 4.6 \mathrm{~mm}$ id), a solvent program starting with $\mathrm{H}_{2} \mathrm{O}$ to methanol for $40 \mathrm{~min}$, and a flow rate of $1.0 \mathrm{~mL} / \mathrm{min}$, with an IT-TOF detector (Shimadzu, MI, Italy) High-resolution mass spectra (HRMS) were obtained using a Shimadzu LCMS-IT-TOF instrument (Shimadzu, MI, Italy). with the following settings: mass range $50-1000 \mathrm{~m} / \mathrm{z}$, ionization system electrospray ion source in positive ion mode, nebulizer gas nitrogen at $1.5 \mathrm{~L} / \mathrm{min}$, dry gas nitrogen at $102 \mathrm{MPa}$ and $250{ }^{\circ} \mathrm{C}$, collision gas argon.

ATR-FTIR spectra of mesoporous silica and catalyst were recorded in the range of $400-4000 \mathrm{~cm}^{-1}$ on a Perkin Elmer spectrometer instrument (Perkin Elmer, MI, Italy ).

NMR spectra were recorded on an Agilent Technologies $300 \mathrm{MHz}$ spectrometer (Agilent Scientific Instrumets Santa Clara, CA, USA); the ${ }^{1} \mathrm{H}$ NMR spectra were referenced to residual isotopic impurity of DMSO-d6 (2.50 ppm); the ${ }^{13} \mathrm{C}$ NMR spectra $(75 \mathrm{MHz})$ were referenced to DMSO-d6 (39.52 ppm).

Elemental analyses and XPS spectra were obtained by X-ray photoelectron spectroscopy (XPS) on a Scanning XPS Microprobe (PHI 5000 Versa Probe II, Physical Electronics) (Physical Electronic, Monterotondo, RM, Italy).equipped with a monochromatic $\mathrm{Al} \mathrm{K \alpha}$ X-ray source (1486.6 eV), operating at $15 \mathrm{kV}$ and $24.8 \mathrm{~W}$, with a spot of $100 \mu \mathrm{m}$. Survey $(0-1200 \mathrm{eV})$ and high-resolution spectra (C1s, O1s, Si2p and La3d5/2) were recorded in FAT (Fixed Analyzer Transmission) mode at a pass energy of 117.40 and $29.35 \mathrm{eV}$, respectively. The analyzer energy resolution, evaluated on the FWHM Ag 3d5/2 photoemission line, was $0.7 \mathrm{eV}$ for a pass energy of $29.35 \mathrm{eV}$. Surface charging was compensated using a dual beam charge neutralization, with a flux of low energy electrons $(\approx 1 \mathrm{eV})$ combined with very low energy positive $\mathrm{Ar}^{+}$ions $(10 \mathrm{eV})$. The hydrocarbon component of the $\mathrm{C} 1 \mathrm{~s}$ spectrum was used as internal standard for charging correction, and it was fixed at $285.0 \mathrm{eV}$ [39]. All spectra were collected at an angle of $45^{\circ}$ with respect to the sample surface. The best fitting of the C1s signal was carried out with MultiPak (Physical Electronics) data processing software (Version 9.0 Physical Electronic, Monterotondo, RM, Italy). Atomic concentrations were determined from the high-resolution spectra (Version 9.0 Physical Electronic, Monterotondo, RM, Italy) after subtracting a Shirley-type background.

BET (Brunauer-Emmett-Teller) specific surface area was obtained by the $\mathrm{N}_{2}$ adsorption-desorption method on powder samples using an Autos orb IQ Chemo TCD (Quantachrome Instruments, Boynton Beach, FL, USA). Samples ( $500 \mathrm{mg}$ ) were pre-treated at $77 \mathrm{~K}$ for $2 \mathrm{~h}$ before $\mathrm{N}_{2}$ adsorption.

The powder X-ray diffraction (PXRD) spectra were acquired at room temperature by depositing ground powders of each sample onto a $\mathrm{Si}$ wafer (zero background) which was rotated $(0.5 \mathrm{~Hz})$ during spectrum acquisition. The spectra were acquired with a X'PERT-PRO powder diffractometer from Panalytical (Malvern Panalytical Company, Malvern, UK ), using CuK $\alpha$ radiation $(\lambda=1.54059 \AA)$, a solid state detector (PIXcel), and a parabolic MPD mirror for Cu radiation. The PXRD spectra were recorded in the range 3.99-99.99 $(2 \Theta)$ applying a step size of $0.0263^{\circ}$ and a counting time of $63.24 \mathrm{sec}$.

SEM-EDS analyses were performed with an electron microscope FESEM-EDX Carl Zeiss Sigma (Zeiss Sigma Company, MI, Italy) 300 VP. The samples were fixed on aluminum stubs and then sputtered with graphite using a Sputter Quorum Q150. Additionally, the chemical composition was determined by EDX under the scanning electron microscope and X-ray diffraction.

The dimension of molecules was performed with Chem3D software (Version 8.0 Ultra, CambridgeSoft Corporation PerkinElmer Informatics).

\subsection{Preparation of the Mesoporous Catalyst La(III)O-KIT-6 (2)}

Catalyst was prepared according to a known procedure [24] by the impregnation/annealing of lanthanum nitrate on mesoporous silica gel. In the first instance, silica gel support was prepared by dissolving $900 \mathrm{mg}$ of surfactant $\mathrm{P}_{123}(0.15 \mathrm{mmol}$, average $\mathrm{Mn} 5800), 1.11 \mathrm{~mL}$ of $\mathrm{n}$-butanol $(\rho 0.81 \mathrm{~g} / \mathrm{mL}$, $12.13 \mathrm{mmol}$ ), and $1.43 \mathrm{~mL}$ of $\mathrm{HCl}$ concentration ( $37 \mathrm{wt} \%$ ) in $32.55 \mathrm{~mL}$ of distilled water. To this solution, $2.07 \mathrm{~mL}(\rho 0.933 \mathrm{~g} / \mathrm{mL}, 9.27 \mathrm{mmol}$ ) of tetraethylorthosilicate (TEOS) were added, and the suspension was stirred at $35^{\circ} \mathrm{C}$ for $24 \mathrm{~h}$. The mixture was heated for a further $24 \mathrm{~h}$ in autoclave at $100{ }^{\circ} \mathrm{C}$ for the 
hydrothermal treatment, followed by filtration. The solid residue was washed, dried at $80^{\circ} \mathrm{C}$ for $12 \mathrm{~h}$, and calcined at $550{ }^{\circ} \mathrm{C}$ for $5 \mathrm{~h}$ to remove the organic template. The silica gel was labeled as KIT-6.

Then, $250 \mathrm{mg}$ of KIT- 6 were suspended into a solution containing $1.52 \mathrm{~g}$ of lanthanum nitrate hexahydrate $\left(\mathrm{La}\left(\mathrm{NO}_{3}\right)_{3} \cdot 6 \mathrm{H}_{2} \mathrm{O}(3.5 \mathrm{mmol})\right.$ and $672 \mathrm{mg}$ of citric acid $\left(\mathrm{C}_{6} \mathrm{H}_{8} \mathrm{O}_{7}, 3.5 \mathrm{mmol}\right)$, as a chelating agent, dissolved in $10 \mathrm{~mL}$ of water/ethanol $(1: 3 \mathrm{v} / \mathrm{v})$. The mixture was heated under reflux for $24 \mathrm{~h}$. Finally, the solvent was evaporated at $100{ }^{\circ} \mathrm{C}$ for $12 \mathrm{~h}$, and the solid residue was calcined at $700{ }^{\circ} \mathrm{C}$ for $5 \mathrm{~h}$. This synthesized catalyst was labeled as La(III)O-KIT-6 (2).

\subsection{Catalytic Tests}

First, $5 \mathrm{~g}$ of glycerol (1) (54 mmol) and $100 \mathrm{mg}$ of catalyst (2) (2 wt \%) were charged into a batch reactor connected to a Dean-Stark system and kept at $240^{\circ} \mathrm{C}$ under $\mathrm{N}_{2}$ atmosphere. Oligomerization conversions at 8,16 , and $24 \mathrm{~h}$ were determined by monitoring the water formation into the distillation trap, [32,33] and further confirmed by GC/MS analyses of reaction mixture by means of a preliminary silylation. [39] In a typical derivatization procedure, $150 \mathrm{mg}$ of reaction mixture was treated into a $10 \mathrm{~mL}$ centrifuge tube with excess amounts $(1.00 \mathrm{~g}$ ca.) of the silylating reagent composed by hexamethyldisi-lazane:trimethylchlorosilane:pyridine in a 3:1:9 weight ratio. The tube was stirred for $5 \mathrm{~min}$ and incubated at room temperature for $30 \mathrm{~min}$, causing the precipitation of $\mathrm{NH}_{4} \mathrm{Cl}$ as a white solid. Then, $20 \mu \mathrm{L}$ of 3,5-dimethylanisole were added to the mixture as an external standard. After centrifugation at $2500 \mathrm{rpm}$ for $5 \mathrm{~min}$, the clear supernatant was analyzed by GC-MS. For the reaction at $24 \mathrm{~h}$, the catalyst was separated by centrifugation and washed with methanol. The recovered catalyst was dried, calcined at $700{ }^{\circ} \mathrm{C}$ to remove the organic phase from the pores, and re-used for further runs at $24 \mathrm{~h}$. The reaction mixture was analyzed by liquid chromatography coupled with high-resolution mass spectrometry, using an LC-Electrospray ionization Ion Trap-TOF mass spectrometry instrument equipped with a $\mathrm{C} 18$ column, using a gradient water-methanol and a mass range of $50-1000 \mathrm{~m} / \mathrm{z}$.

\section{Conclusions}

Several studies have recently been conducted to improve the glycerol polymerization process and to obtain linear molecules, which lay the path to new bio-based polymers with many potential applications in several fields, including biomedicine and 3D printing [40]. To this aim, it is essential to drive the polymerization selectivity, especially toward linear oligomers. The hybrid catalyst La(III)OKIT-6 (2) proposed in this work, prepared by the impregnation of lanthanum (III) on mesoporous silica gel, shows a superior linear selectivity and affords better yields of tetramer compared to most of the analogous catalysts recently reported. This high selectivity can be ascribed to both the amphoteric properties of lanthanum oxide and the mesoporous structure of the support that, due to the pore sizes, seems to be suitable for the accommodation of linear oligomers enhancing the linear selectivity. Further advantages such as the easy workup and the absence of La (III) leaching suggests that this protocol marks a significant step forward compared to the current literature on this important issue.

Supplementary Materials: The following are available online at http://www.mdpi.com/2073-4344/10/10/1170/s1, Figure S1. C1s spectra for the catalyst La(III)OKIT-6 before (A) and after (B) three recycling experiments; Figure S2. Survey spectrum of recovered La(III)O KIT-6 after three recycling experiments; Figure S3. N2 adsorption-desorption isotherm for KIT-6; Figure S4. N2 adsorption-desorption isotherm for La(III)O-KIT-6 catalyst 2; Figure S5. N2 adsorption-desorption isotherm for La(III)O-KIT-6 after III cycle (2') Figure S6. SEM image $100 \mu$ m of KIT-6; Figure S7. SEM image $20 \mu \mathrm{m}$ of KIT-6; Figure S8. SEM image $100 \mu \mathrm{m}$ of La(III)O KIT-6; Figure S9. SEM image $100 \mu \mathrm{m}$ of La(III)O KIT-6 after three recycling experiments; Figure S10. SEM image $20 \mu \mathrm{m}$ of La(III) OKIT-6 after three recycling experiments; Figure S11. HPLC chromatograms; Figure S12. GC/MS analysis of the 1st catalytic run with La(III)OKIT-6; Figure S13. GC/MS analysis of 2nd catalytic run with La(III)@KIT-6; Figure S14. GC/MS analysis of 3rd catalytic run with La(III)O-KIT-6. Figure S15. HRMS of linear and cyclic hybrid oligomers; Figure S16. 1H-NMR spectrum of reaction mixture 24h in DMSO, Figure S17. 13C-NMR spectrum of reaction mixture $24 \mathrm{~h}$ in DMSO 
Author Contributions: D.C.: investigation experimental design; M.C.: investigation IT/TOF; A.M. (Antonella Milella): investigation XPS; W.O.: investigation XRD; A.M. (Alfonso Maffezoli): Data curation; A.N. Data curation and review editing; C.F. methodology, data curation and review editing; L.D.: conceptualization, investigation, data curation, writing manuscript and corresponding author. All authors have read and agreed to the published version of the manuscript.

Funding: This work is partially supported by funds from European Union-19 FESR "PON Ricerca e Innovazione 2014-2020. Progetto: 20 Energie per l'Ambiente TARANTO-Cod. ARS01_00637"

Acknowledgments: Antonella Russo AD Greenswitch factory for glycerol donation.

Conflicts of Interest: The authors declare no conflict of interest.

\section{References}

1. Gonçalves, M.; Castro, C.S.; Oliveira, L.C.; Carvalho, W.A. Green acid catalyst obtained from industrial wastes for glycerol etherification. Fuel Process. Technol. 2015, 138, 695-703. [CrossRef]

2. Ortiz, A.G.; Arias, K.S.; Climent, M.J.; Corma, A.; Iborra, S. One-Pot Synthesis of Biomass-Derived Surfactants by Reacting Hydroxymethylfurfural, Glycerol, and Fatty Alcohols on Solid Acid Catalysts. ChemSusChem 2018, 11, 2870-2880. [CrossRef]

3. Meyer, T.H.; Chesnokov, G.A.; Ackermann, L. Cobalta-Electrocatalyzed C-H Activation in Biomass-Derived Glycerol: Powered by Renewable Wind and Solar Energy. ChemSusChem 2020, 13, 668-671. [CrossRef]

4. Sivaiah, M.; Robles-Manuel, S.; Valange, S.; Barrault, J. Recent developments in acid and base-catalyzed etherification of glycerol to polyglycerols. Catal. Today 2012, 198, 305-313. [CrossRef]

5. Stuhler, H. Process for the Preparation of Polyglycerols. US 9,956,547 B2. U.S. Patent 9,956,547 B2, 1 May 2018.

6. Ionescu, M.; Petrović, Z.S. High Functionality Polyether Polyols Based on Polyglycerol. J. Cell. Plast. 2010, 46, 223-237. [CrossRef]

7. Wilms, D.; Stiriba, S.-E.; Frey, H. Hyperbranched Polyglycerols: From the Controlled Synthesis of Biocompatible Polyether Polyols to Multipurpose Applications. Accounts Chem. Res. 2010, 43, $129-141$. [CrossRef]

8. Thomas, A.; Müller, S.S.; Frey, H. Beyond Poly (ethylene glycol): Linear Polyglycerol as a Multifunctional Polyether for Biomedical and Pharmaceutical Applications. Biomacromolecules 2014, 15, 1935-1954. [CrossRef]

9. Cassel, S.; Debaig, C.; Benvegnu, T.; Chaimbault, P.; Lafosse, M.; Plusquellec, D.; Rollin, P. Original synthesis of linear, branched and cyclic oligoglycerol standards. Eur. J. Org. Chem. 2001, 2, 875-896. [CrossRef]

10. Medeiros, M.A.; Araujo, M.H.; Augusti, R.; de Oliveira, L.C.A.; Lago, R.M. Acid-catalyzed oligomerization of glycerol investigated by electrospray ionization mass spectrometry. J. Braz. Chem. Soc. 2009, 20, 1667-1673. [CrossRef]

11. Ionescu, M.; Petrović, Z.S. On the Mechanism of Base-Catalyzed Glycerol Polymerization and Copolymerization. Eur. J. Lipid Sci. Technol. 2018, 120, 1800004. [CrossRef]

12. Richter, M.; Krisnandi, Y.K.; Eckelt, R.; Martin, A. Homogeneously catalyzed batch reactor glycerol etherification by $\mathrm{CsHCO}_{3}$. Catal. Commun. 2008, 9, 2112-2116. [CrossRef]

13. Martin, A.; Richter, M. Oligomerization of glycerol-A critical review. Eur. J. Lipid Sci. Technol. 2010, 113, 100-117. [CrossRef]

14. Ruppert, A.M.; Meeldijk, J.D.; Kuipers, B.W.M.; Erné, B.H.; Weckhuysen, B.M. Glycerol Etherification over Highly Active CaO-Based Materials: New Mechanistic Aspects and Related Colloidal Particle Formation. Chem. A Eur. J. 2008, 14, 2016-2024. [CrossRef]

15. Calatayud, M.; Ruppert, A.M.; Weckhuysen, B.M. Theoretical Study on the Role of Surface Basicity and Lewis Acidity on the Etherification of Glycerol over Alkaline Earth Metal Oxides. Chem. A Eur. J. 2009, 15, 10864-10870. [CrossRef] [PubMed]

16. García-Sancho, C.; Moreno-Tost, R.; Mérida-Robles, J.M.; Santamaría-González, J.; Jiménez-López, A.; Torres, P.M. Etherification of glycerol to polyglycerols over MgAl mixed oxides. Catal. Today 2011, 167, 84-90. [CrossRef]

17. Clacens, J.-M.; Pouilloux, Y.; Barrault, J. Selective etherification of glycerol to polyglycerols over impregnated basic MCM-41 type mesoporous catalysts. Appl. Catal. A Gen. 2002, 227, 181-190. [CrossRef] 
18. Laurenza, A.G.; Casiello, M.; Anzivino, M.; Caputo, D.; Catucci, L.; Dell'Anna, M.M.; Fusco, C.; Rizzi, V.; Pantone, V.; D'Accolti, L.; et al. Green Procedure for One-Pot Synthesis of Azelaic Acid Derivatives Using Metal Catalysis. Recent Innov. Chem. Eng. (Formerly Recent Patents Chem. Eng.) 2019, 11, 185-191. [CrossRef]

19. Goscianska, J.; Ptaszkowska-Koniarz, M.; Frankowski, M.; Franus, M.; Panek, R.; Franus, W. Removal of phosphate from water by lanthanum-modified zeolites obtained from fly ash. J. Colloid Interface Sci. 2018, 513, 72-81. [CrossRef]

20. Roy, T.; Sahani, S.; Sharma, Y.C. Green synthesis of biodiesel from Ricinus communis oil (castor seed oil) using potassium promoted lanthanum oxide catalyst: Kinetic, thermodynamic and environmental studies. Fuel 2020, 274, 117644. [CrossRef]

21. Barrault, J.; Clacens, J.-M.; Pouilloux, Y. Selective Oligomerization of Glycerol Over Mesoporous Catalysts. Top. Catal. 2004, 27, 137-142. [CrossRef]

22. Monopoli, A.; Cotugno, P.; Iannone, F.; Ciminale, F.; Dell'Anna, M.M.; Mastrorilli, P.; Nacci, A. Ionic-LiquidAssisted Metal-Free Oxidative Coupling of Amines to Give Imines. Eur. J. Org. Chem. 2014, 2014, 5925-5931. [CrossRef]

23. Pantone, V.; Laurenza, A.G.; Annese, C.; Fracassi, F.; Fusco, C.; Nacci, A.; Russo, A.; D'Accolti, L. Methanolysis of epoxidized soybean oil in continuous flow conditions. Ind. Crop. Prod. 2017, 109, 1-7. [CrossRef]

24. Wang, Y.; Cui, X.; Li, Y.; Shu, Z.; Chen, H.; Shi, J.L. A simple co-nanocasting method to synthesize high surface area mesoporous $\mathrm{LaCoO} 3$ oxides for $\mathrm{CO}$ and $\mathrm{NO}$ oxidations. Microporous Mesoporous Mater. 2013, 176, 8-15. [CrossRef]

25. van der Heijden, A.W.A.M.; Bellière, V.; Alonso, L.E.; Daturi, M.; Manoilova, A.O.V.; Weckhuysen, B.M. Destructive Adsorption of CCl4over Lanthanum-Based Solids: Linking Activity to Acid-Base Properties. J. Phys. Chem. B 2005, 109, 23993-24001. [CrossRef]

26. van der Heijden, A.W.A.M.; Ramos, M.G.; Weckhuysen, B.M. Intermediates in the Destruction of Chlorinated C1 Hydrocarbons on La-Based Materials: Mechanistic Implications. Chem. A Eur. J. 2007, 13, 9561-9571. [CrossRef]

27. Shokri, B.; Firouzjah, M.A.; Hosseini, S.I. FTIR analysis of silicon dioxide thin film deposited by Metal organic-based PECVD. In Proceedings of the 19th International Symposium on Plasma Chemistry Society, Bochum, Germany, 27-31 July 2009; Volume 2631.

28. Salavati-Niasari, M.; Hosseinzadeh, G.; Davar, F. Synthesis of lanthanum hydroxide and lanthanum oxide nanoparticles by sonochemical method. J. Alloy. Compd. 2011, 509, 4098-4103. [CrossRef]

29. Choi, J.; Chung, Y.H. Preparation of Lanthanum Oxide and Lanthanum Oxycarbonate Layers on Titanium by Electrodeposition with Organic Solution. J. Nanomater. 2016, 2016, 1-13. [CrossRef]

30. Przekop, R.E.; Marciniak, P.; Sztorch, B.; Czapik, A.; Stodolny, M.; Martyła, A. One-pot synthesis method of $\mathrm{SiO} 2-\mathrm{La} 2 \mathrm{O} 2 \mathrm{CO} 3$ and $\mathrm{SiO} 2-\mathrm{La} 2 \mathrm{O} 3$ systems using metallic lanthanum as a precursor. J. Non-Cryst. Solids 2019, 520, 119444. [CrossRef]

31. Ghiasi, M.; Malekzadeh, A. Synthesis, characterization and photocatalytic properties of lanthanum oxy-carbonate, lanthanum oxide and lanthanum hydroxide nanoparticles. Superlattices Microstruct. 2015, 77, 295-304. [CrossRef]

32. Salehpour, S.; Dubé, M.A. Towards the Sustainable Production of Higher-Molecular-Weight Polyglycerol. Macromol. Chem. Phys. 2011, 212, 1284-1293. [CrossRef]

33. Dube, S.M.; Salehpour, S. Methods for Making Polyglycerol. U.S. Patent 8,704,005B2, 22 April 2014.

34. Zambonin, C.G.; Calvano, C.D.; D’Accolti, L.; Palmisano, F. Laser desorption/ionization time-of-flight mass spectrometry of squalene in oil samples. Rapid Commun. Mass Spectrom. 2005, 20, 325-327. [CrossRef] [PubMed]

35. Gholami, Z.; Abdullah, A.Z.; Lee, K.T. Heterogeneously catalyzed etherification of glycerol to diglycerol over calcium-lanthanum oxide supported on MCM-41: A heterogeneous basic catalyst. Appl. Catal. A Gen. 2014, 479, 76-86. [CrossRef]

36. Souza, J.; Souza, P.M.; De Souza, P.P.; Sangiorge, D.L.; Pasa, V.M.; Oliveira, L.C. Production of compounds to be used as fuel additive: Glycerol conversion using $\mathrm{Nb}$-doped $\mathrm{MgAl}$ mixed oxide. Catal. Today 2013, 213, 65-72. [CrossRef]

37. Lee, J.H.; Park, S.K.; Ryu, J.-B.; Lee, H.; Lee, J.S. Solventless Catalytic Etherification of Glycerol Using Acetate Salts as Efficient Catalysts. Bull. Korean Chem. Soc. 2018, 39, 722-725. [CrossRef] 
38. Casiello, M.; Monopoli, A.; Cotugno, P.; Milella, A.; Dell'Anna, M.M.; Ciminale, F.; Nacci, A. Copper (II) chloride-catalyzed oxidative carbonylation of glycerol to glycerol carbonate. J. Mol. Catal. A Chem. 2014, 381, 99-106. [CrossRef]

39. Beamson, G.; Briggs, D. High Resolution XPS of Organic Polymers: The Scienta ESCA300 Database. J. Chem. Educ. 1993, 70, A25. [CrossRef]

40. Corcione, C.E.; Gervaso, F.; Scalera, F.; Montagna, F.; Sannino, A.; Maffezzoli, A. The feasibility of printing polylactic acid-nanohydroxyapatite composites using a low-cost fused deposition modeling 3D printer. J. Appl. Polym. Sci. 2016, 134, 134. [CrossRef]

(C) 2020 by the authors. Licensee MDPI, Basel, Switzerland. This article is an open access article distributed under the terms and conditions of the Creative Commons Attribution (CC BY) license (http://creativecommons.org/licenses/by/4.0/). 